\title{
As políticas públicas ambientais no jornal Gazeta do Povo: \\ Como se dá a cobertura das ações governamentais para o meio ambiente
}

\author{
Michele Goulart Massuchin* \\ Emerson Urizzi Cervi**
}

Artigo recebido em:

19 de setembro de 2010

Aprovado em:

4 de outubro de 2010

* Mestranda em

Ciência Política pela Universidade Federal do Paraná (UFPR) e bacharel em Comunicação

Social - Jornalismo pela Universidade Estadual de Ponta Grossa (UEPG).

Membro do Grupo de Pesquisa em Comunicação e Política da UFPR Bolsista do Programa REUNI 2010/2011.

mimassuchin@hotmail.com

** Doutor em Ciência Política pelo IUPE-RJ, Mestre em Sociologia

Política pela UFPR

e graduado em

Comunicação Social pela UEPG. Professor

do departamento

de comunicação da

UEPG, professor do

departamento de

ciências sociais da

UFPR e coordenador do grupo de pesquisa

em Comunicação,

Política e Atores Sociais (UEPG/UFPR).
Resumo: Este artigo tem por objetivo observar de que forma o jornal Gazeta do Povo (Curitiba) aborda as políticas públicas ambientais durante o período de 2000 a 2009. As políticas são resultados da atenção que o governo dispõe para determinados temas e da necessidade de uma grande quantidade de pessoas, que no caso do tema meio ambiente ganhou destaque a partir das últimas décadas do século $\mathrm{XX}$, quando os problemas ambientais chamaram a atenção da sociedade. Nesse cenário, os meios de comunicação atuam como espaço de debate, onde podemos observar em que medida se dá a discussão pública sobre o assunto e também como forma de agendar o debate na esfera pública. O trabalho apresenta os dados empíricos que possibilitam observar quais os temas mais frequentes e em que momentos do desenvolvimento dessas ações a mídia dá mais atenção e faz a cobertura. A hipótese inicial que norteia o trabalho é que os temas não aparecem de forma equilibrada e a mídia também apresenta uma cobertura fragmentada, abordando o assunto apenas como forma de divulgação da agenda governamental e não do debate anterior a criação de políticas nem na sua avaliação.

Palavras-chave: Política pública ambiental; Gazeta do Povo; debate público.

\section{Environmental public policies on Gazeta do Povo newspaper: Hows is the coverage of government actions for environment}

Abstract: This text observe how the newspaper Gazeta do Povo (Curitiba) addresses environmental public policies during the period 2000 to 2009 . The policies are the result of the attention that the government provides for certain topics and the need for a large number of people, in which case the environmental theme was highlighted from the last decades of the twentieth century, when the environmental problems brought to the attention of society . In this scenario, the media act as a space for debate, where we can see to what extent it gives the public discussion on the subject and also as a way to schedule the public sphere. The paper presents empirical data that allow you to observe what the most common themes and moments in which development of these actions the media gives more attention and makes the cover. The initial hypothesis that guides the work is that the themes do not appear in a balanced way and the media coverage has also fragmented, addressing the issue only as a means of disseminating the government agenda and not the debate preceding the establishment of policies and in its assessment.

Keywords: Environmental public policies; Gazeta do Povo; public debate. 


\section{Introdução}

compreensão da mídia como espaço público e ator influente nas modificações que ocorrem na Esfera Pública, apresentam-a como um agente importante nas sociedades contemporâneas nos mais diversos aspectos, desde seu papel de mediador, potencializador de debate público, agendamento de temas para discussão, espaço onde se materializam as discussões da esfera pública etc. Essas características ajudam a compreender por que é relevante identificar como um assunto - as políticas ambientais - aparece no jornal, seja pelo espaço que recebe ou pelos atores que ganham visibilidade. Segundo Miguel (2002), a relação entre a esfera política e midiática se intensificou nos últimos anos e os meios de comunicação ocupam cada vez mais um espaço de destaque na sociedade, resultado do seu desenvolvimento ao longo do século XX. Ao observar como as políticas públicas aparecem na mídia parte-se do pressuposto da importância que esta ocupa na potencialização do debate público a partir da difusão das informações e agendamento, principalmente pelo espaço que representa na cristalização do próprio debate. Olhando para o jornal, neste caso, é possível observar, em grande parte, como se dá o debate sobre as ações ambientais na sociedade.

Marques (2008) e Hansen (2007), por exemplo, consideram que os meios de comunicação podem converter-se em arenas de debate. Dessa forma, na tentativa de compreender como se dá o debate sobre as políticas ambientais na sociedade contemporânea, os meios de comunicação são considerados como o espaço onde se materializa o debate público, onde se observam quais são os temas que se tornam mais visíveis para o público e em que momentos a mídia faz a cobertura desse assunto específico.

Porém, é necessário salientar que ao retratar os temas, assim como o embate de idéias, a mídia não os representa fielmente pelas próprias características da produção jornalística, tais como as rotinas produtivas, o tipo de fonte que ganha visibilidade, as influências do mercado, da sociedade, da cultura etc. (SHOEMAKER e VOS, 2009). Os medias acabam cristalizando apenas parte do debate e, dessa forma, atuam como construtores de realidade ao tentar reproduzi-la, o que pode influenciar os leitores, partindo do pressuposto que a mídia agenda os temas para o debate público (McCOMBS e SHAW, 1972) e que pode interferir também a agenda política.

As hipóteses iniciais presentes neste trabalho pressupõem que ao falar de política pública, a mídia apresenta apenas determinados temas, não fazendo uma cobertura equilibrada sobre o assunto, devido as características internas e externas as redações, as quais Shoemaker e Vos (2009) chamam a atenção. Nessa perspectiva, ao olhar para o jornal serão observados quais os temas mais abordados em detrimento de outros, já que os meios de comunicação não são mera retratação da realidade (TUCHMAN, 1993), mas uma parte escolhida e recortada. A segunda hipótese, complementar a primeira, também está relacionada com as escolhas dos meios de comunicação ao fazer a cobertura. A criação de uma nova variável, adaptada das leituras sobre políticas públicas, permite identificar em que momento do ciclo político a mídia promove o debate e dá mais espaço para as ações governamentais. Compreendendo que a cobertura tende a depender de fatores políticos, sociais e econômicos, a 
hipótese é que ela apareça concentrada em apenas alguns momentos do ciclo político, como na divulgação das ações governamentais e não no debate de elaboração ou avaliação das políticas.

Quando observamos como determinado assunto aparece na mídia, partimos também da sua relevância como fonte de informação importante na deliberação e formação da opinião pública, na medida em que as pessoas precisam de conhecimento para discutir e argumentar, neste caso, sobre a agenda e elaboração de novas políticas públicas. Maia (2002) considera os meios de comunicação como importantes na pré-estruturação da esfera pública política. $\mathrm{Na}$ sociedade que se estabelece a partir do início do século XX, a mídia passou a exercer papel central na disseminação de informações. Os meios de comunicação passaram a fazer parte do dia-a-dia dos indivíduos e ganharam espaço relevante na esfera política, por ser espaço de visibilidade, como afirma Miguel (2002).

A pesquisa utiliza o método quantitativo de análise de conteúdo e o período pesquisado é de 2000 a 2009, reunindo por meio da coleta por amostragem cerca de 520 edições do jornal Gazeta do Povo. Nessas edições foram coletadas 367 entradas de textos sobre política ambiental, analisados a partir de numa série de variáveis, das quais algumas aparecem neste texto. O jornal analisado caracteriza-se como um veículo de abrangência e circulação estadual e é produzido em Curitiba. No próximo tópico apresenta-se uma discussão sobre a importância da mídia no cenário contemporâneo. Em seguida são feitas algumas referências sobre as políticas ambientais e o II Plano Nacional de Meio Ambiente - PNMA II - e na última parte do artigo é apresentada a análise empírica e interpretação dos dados coletados.

\section{Meios de comunicação como espaço de debate, visibilidade e agendamento}

Os meios de comunicação são importantes para a visibilidade das discussões públicas e, segundo Gomes (2007), isso é positivo para a democracia, pois contribui para a deliberação pública. "Na reserva, na clausura, também se pode discutir e discutir em profundidade, mas o segredo não faz boa democracia" (GOMES, 2007, p. 9). Tejeiro (2006) considera que a diferença entre o que acontecia nos séculos passados e o que passou a ocorrer principalmente no século XX e início do XXI é que agora os meios de comunicação têm ocupado com mais ênfase esse espaço de visibilidade - abordado por Wilson Gomes fala - na vida política da democracia e se configuram como atores do espaço público (RESENDE, s/d). Os assuntos que aparecem na mídia, seja ela impressa ou eletrônica, passam a ter visibilidade na medida em que os veículos conseguem atingir um grande número de pessoas (ARUGUETE, 2005).

Segundo Aruguete (2005), os acontecimentos que não estão ao alcance dos indivíduos chegam até ele por meio da mídia. Dessa forma, ao falar sobre as políticas públicas ambientais, os meios de comunicação podem ser considerados como mediadores entre os atores sociais e políticos, pois seriam os responsáveis em levar as informações políticas até a sociedade civil. Essa mesma definição é compartilhada por Miguel (2000). De acordo com ele, a mídia 
pode ser considerada como o principal canal de acesso dos cidadãos à informação. E, nesse mesmo viés, os meios de comunicação também se apresentam como instrumento dos líderes políticos para a divulgação de suas mensagens, o que coloca a mídia numa posição central na arena política. Com a característica de mediadora das realidades que não estão a disposição dos atores sociais, a mídia pode atuar como construtora de realidades, segundo Tuchman (1993). E o que explica essa construção que define novas realidades são os fatores que interferem no processo de produção das notícias. Shoemaker e Vos (2009), explicam esse fenômeno pelo processo de Gatekeeping. Segundo os autores o que define a produção final são os diferentes níveis que influenciam na produção: fontes, instituições, rotinas produtivas, jornalista e sistema social. Dessa forma, quando identificamos que um tipo de notícia sobre determinado tema não aparece em detrimento de outro, pode-se dizer que ele não passou por todos os gates. Esse processo complexo ajuda a explicar os resultados presentes nas análises quantitativas das pesquisas e, no caso desta pesquisa, a hipótese inicial a qual parte do princípio que as diferenças na tematização e cobertura existem pelas influências descritas acima.

Esse processo de construção ganha relevância subsequente a publicação das noticias, que é o agendamento do debate, do qual os meios de comunicação fazem parte. Vários autores consideram os meios de comunicação como importantes para agendar os temas para discussão na sociedade (GUARESCHI, 2007). Na medida em que a mídia veicula notícias a respeito de assuntos de interesse público, como, por exemplo, as ações governamentais para o meio ambiente, as quais estariam distantes da sociedade, ela poderia estar contribuindo para o debate na sociedade, estabelecendo temas da agenda pública, por meio da sua capacidade de agendamento, hipótese proposta por McCombs e Shaw (1972). Partindo disso, pode-se afirmar

Sendo mediadora das realidades que não estão à disposição de atores sociais, a mídia atua como construtora de realidades que a mídia possui o poder de dizer sobre o que pensar, o que contribui para a formulação da agenda pública e consequentemente para a formação da agenda política, a partir da formação da opinião pública. O conteúdo midiático, a partir da agenda-setting, se reflete nas discussões públicas, desde as conversa em bares, cafés ou entre vizinhos, ou em casos mais complexos como nas discussões sobre política ou problemas sociais. Dessa forma, é importante compreender a mídia como um processo de construção de realidades e que esses vieses presentes no tipo de cobertura pode influenciar na recepção dos leitores. Ressalta-se, contudo, que essa influência decorrente dos atributos do fato não ocorre sempre da mesma forma e nem em todos os indivíduos.

A influência depende muito do ambiente informacional no qual a pessoa se encontra e o seu nível de informação anterior ao conteúdo jornalístico. Em estudos feitos por Coimbra (2007) sobre as eleições, percebe-se que a influência da mídia ocorre em pessoas de baixo interesse em política e menos informados, as quais não têm uma ligação direta prévia com nenhum partido, mas que ainda possuem interesse pelo assunto. São nessas pessoas que a cobertura midiática provoca efeito. Pessoas bem informadas e com maior interesse não sofrem efeitos da cobertura feita pela mídia. Dessa forma, as predisposições, identidades partidárias, nível de interesse e grau de informação influenciam 
nos efeitos que a mídia pode provocar, atingindo apenas parcela da população que, apesar de se interessar por política, (COIMBRA, 2007), possui baixa estruturação de opiniões e comportamentos.

Marques (2008) apresenta outra função, e talvez uma das mais importantes, que é a capacidade dos meios de converterem-se em arenas de debate. Mas, segundo a autora, essa capacidade ainda é pouco explorada e poucos autores trabalham com essa vertente de estudos. Nesse caso, os meios de comunicação são considerados como próprios espaços de debates como propôs Hansen (2007) ao falar de arenas de conflitos. Na parte seguinte do texto são apresentadas algumas referências sobre as políticas públicas, objeto de pesquisa nos jornais.

\section{As políticas ambientais: uma breve revisão bibliográfica}

Segundo Souza (2006), foi a partir das políticas econômicas que as polícias públicas em geral, incluindo as de meio ambiente, ganharam mais destaque. Apesar de parecerem conceitos bastante teóricos, as políticas podem ser traduzidas em termos mais visíveis. Para Souza (2006), após formuladas, elas desdobram-se em planos e programas que, quando implementados, ficam submetidos a sistemas de acompanhamento e avaliação. Para um assunto - tal como o meio ambiente - ganhar atenção do governo e passar a compor a agenda política, é necessário que seja considerado importante para uma grande quantidade de pessoas. Segundo Capella (2005), uma questão passa a fazer parte da agenda governamental quando desperta a atenção e o interesse também dos formuladores de políticas. No caso do tema meio ambiente, pode-se considerar que no final do século XX, com as descobertas científicas e pesquisas ambientais, o poder público passou a dar atenção ao tema meio ambiente após verificar indicadores e uma série de acontecimentos que chamaram a atenção das pessoas, além da pressão dos movimentos que surgiram na sociedade. As políticas precisam representar valores compartilhados, ter uma aceitação do publico geral e, principalmente, não entrarem em conflito com outros grupos.

Apesar da infinidade de problemas que envolvem o meio ambiente, entretanto, a questão ambiental ainda não é considerada foco nas políticas públicas (LIMA, 2008), mesmo sabendo-se que elas deveriam ocupar espaço de destaque, tanto na sociedade quanto para políticos, uma vez que elas interferem nas outras ações da administração pública. Para o autor, essa falta de atenção em relação as políticas ambientais é resultado de um processo histórico e cultural. Porém nas últimas décadas, reflexo da Eco-92 que aconteceu no Brasil, o Governo Federal, em parceria com os demais setores políticos criaram novas leis, programas e metas para o país. Nesse contexto, criou-se o Plano Nacional de Meio Ambiente, o qual durante os últimos dez anos (2000-2009), compôs uma série de atividades num momento em que o tema meio ambiente tem feito parte do debate público. O Programa Nacional de Meio Ambiente II PNMA II - que teve início em 2000, com a sua primeira fase, e término em 2009, com a terceira e última fase. O programa foi instituído no Brasil no início dos anos 1990 (PNMA I) com o objetivo de fortalecer o Sistema Nacional de 
Meio Ambiente e seus órgãos executores, tais como o IBAMA, as secretarias de meio ambiente, e agências ambientais estaduais e municipais. A partir do ano de 2000, iniciou a segunda etapa dos trabalhos centralizando-se esforços na capacidade gestora dos Estados Federados e dos executores dos Sistemas Estaduais de Meio Ambiente. O PNMA II foi financiado por meio de acordo de empréstimo entre o Governo Brasileiro e o Banco Mundial (BIRD), sendo investido o valor total de 300 milhões de dólares para aplicação e desenvolvimento de projetos em todo o país.

Observando as atividades governamentais implantadas durante a última década, percebe-se que o assunto tem ganhado destaque nas discussões públicas, seja pelos impasses na implantação de novas leis, ineficácia das ações, entre outros assuntos. Dessa forma, em paralelo com a temática ambiental, as ações governamentais passaram a ser um assunto público fazendo parte da agenda de discussão da mídia, da sociedade e dos políticos. Assim, torna-se relevante identificar de que forma as políticas ambientais, durante a implantação e execução do PNMA II, aparecem e ganham visibilidade na mídia impressa. No tópico seguinte são apresentados os dados referentes aos temas das políticas que aparecem no jornal Gazeta do Povo e as etapas do ciclo político em que a mídia faz cobertura.

\section{Política ambiental no jornal Gazeta do Povo: temas e etapas do ciclo político}

O objetivo desse artigo é observar quais os temas e o tipo de abordagem que o jornal faz das políticas públicas ambientais. Para isso a pesquisa utiliza a metodologia quantitativa de análise de conteúdo. Neste texto foram utilizados dados referentes à coleta realizada no período de 2000 a 2009, no Jornal Gazeta do Povo, em que foram analisadas cerca de 520 edições e coletadas informações de 367 textos. A escolha do método está relacionada ao objetivo da pesquisa, que é relacionar os dados da realidade com conceitos e teorias já existentes. Para a utilização desse método são necessárias algumas orientações, tais como a exigência de um grande número de casos para a possibilidade de detectar diferenças significativas e poder fazer inferência na realidade (DAVIS, 1976). Na pesquisa quantitativa, o processo de coleta de evidências na realidade parte sempre de idéias e conceitos já existentes, que foram resultantes de outros estudos e que, por meio de técnicas, podem ser medidas e contadas (CERVI, 2009). Neste caso, discutimos os dados encontrados na realidade com os conceitos de construção das notícias e interferências internas e externas na produção proposto por Tuchman (1976) e Shoemaker e Vos (2009), conceitos esses que podem ajudar a explicar os dados, refutando ou afirmando as hipóteses iniciais que nortearam o trabalho. Além disso, por se tratar de um longo período de análise, a qual é denominada por Bauer (2002) como análise por semana composta, a pesquisa foi realizada por amostragem.

Para compreender como o Jornal Gazeta do Povo abordou as políticas ambientais durante o período pesquisado, apresentamos abaixo os resultados referentes à variável tema da política pública e etapa do ciclo político em que a 
mídia faz a cobertura dessas ações. A tabela a seguir (Tabela 1) apresenta as frequências simples dos temas que mais apareceram no jornal.

\begin{tabular}{lcc}
\multicolumn{1}{c}{ Tema da política pública } & Frequência & $\%$ \\
\hline Educação Ambiental & 8 & 2,2 \\
Sustentabilidade & 132 & 36,0 \\
Preservação de Áreas Ambientais & 83 & $\mathbf{2 2 , 6}$ \\
Legislação & 69 & 18,8 \\
Outro & 24 & 6,5 \\
Políticas/devastação & 51 & 13,9 \\
Total & 367 & 100,0
\end{tabular}

TABELA 1 - Temas das políticas públicas presentes no jornal Fonte: Autores

Os dados observados na tabela indicam que as políticas ambientais, dependendo do tema, ganham mais visibilidade. As políticas de sustentabilidade são as que mais aparecem com 36\% (132) das entradas, mas em contrapartida as políticas de educação ambiental aparecem em apenas 2,2\% (8) das entradas. Mesmo que haja diferença no tipo de política aprovada e executada pela elite política, o fato de o tema aparecer apenas oito vezes durante os dez anos analisados é pouco em relação à presença das políticas de sustentabilidade, preservação e legislação, por exemplo. Como Shoemaker e Vos (2009) afirmam, a produção sofre influência de diferentes setores da sociedade até chegar às páginas do jornal e ao olhar a desvantagem do debate sobre um assunto em relação a outro podemos fazer algumas considerações. Como a agenda midiática sofre constante influência da agenda política (ARUGUETE, 2005), é possível que essa diferença esteja relacionada com o agendamento que as outras esferas, especialmente a política, fazem na mídia, dando atenção apenas para um tema e não outro. Como a pesquisa analisa 10 anos de cobertura, o gráfico abaixo (Gráfico 1) apresenta o percentual de entradas de cada tema por ano pesquisado.

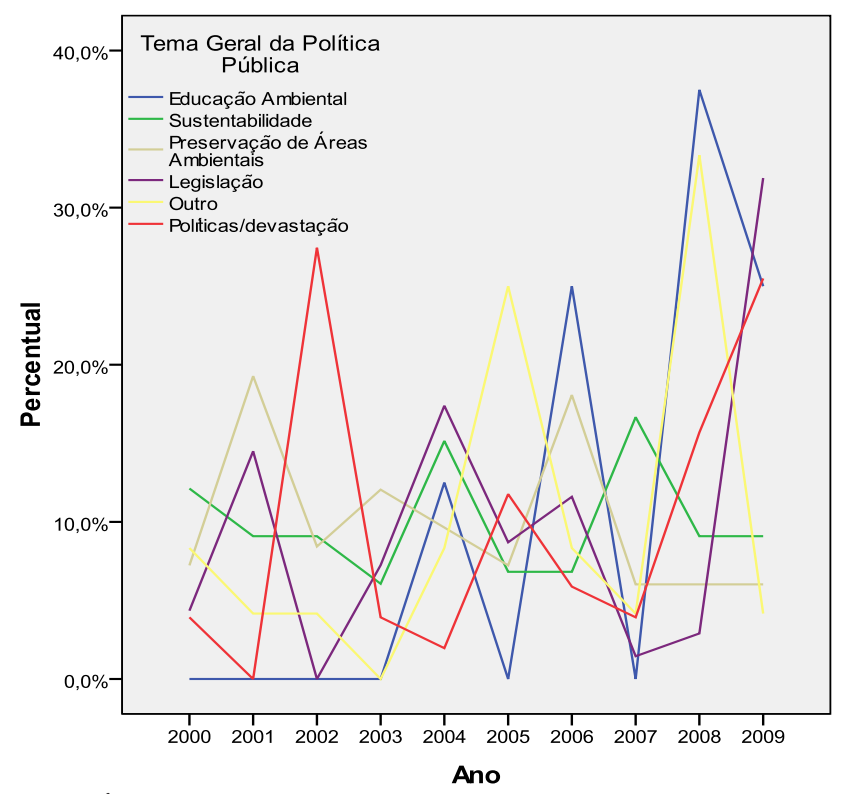

GRÁFICO 1 - Tema da política durante o período analisado

Fonte: Autores 
O gráfico permite identificar que os temas aparecem em constante oscilação durante o mesmo, o que está relacionado com acontecimentos específicos durante o período e que não há presença constante do debate sobre cada um dos assuntos. O teste de Independência de médias Qui-quadrado também identificou que há relação entre as duas variáveis ${ }^{1}$, pois apresentou um sig. de 0,000. Além das políticas de sustentabilidade aparecerem em maior quantidade do que as demais, elas aparecem todos os anos quase na mesma quantidade, sem apresentar grandes oscilações. $\mathrm{O}$ tema legislação apresentou queda e posteriormente um aumento bastante significativo, o que está relacionado ao debate sobre o novo código florestal que apareceu em diversas entradas coletadas. É possível identificar ainda que só há presença das políticas de educação ambiental a partir de 2004. Políticas contra devastação possuem dois períodos de pico (2002 e 2009), quando aparecem textos sobre a execução de políticas contra desmatamento, atuação do IBAMA na apreensão de madeira, entre outros casos. As políticas de preservação se apresentam também de forma mais estável, assim como as de sustentabilidade. De forma geral, alguns temas aparecem com mais frequência (sustentabilidade e preservação), enquanto outros ganham mais visibilidade apenas em períodos específicos, quase não sendo observados nos demais. Sustentabilidade e preservação, além de aparecerem em maior quantidade, estão presentes de forma mais estável durante todo o período. Na tabela abaixo apresentamos os dados referentes à relação entre o tema e o enquadramento, com o objetivo de identificar se as políticas estão relacionadas a um tema específico ou são permanentes no jornal, independente dos fatos diários.

\begin{tabular}{|l|r|r|r|r|r|}
\hline Enquadramento & Sustentabilidade & Preservação & Legislação & $\begin{array}{c}\text { Pol/ } \\
\text { devastação }\end{array}$ & Total \\
\hline Episódico & 53 & 54 & 37 & 29 & 173 \\
& $46,5 \%$ & $66,7 \%$ & $67,3 \%$ & $63,0 \%$ & $58,4 \%$ \\
\hline Temático & 61 & 27 & 18 & 17 & 123 \\
& $53,5 \%$ & $33,3 \%$ & $32,7 \%$ & $37,0 \%$ & $41,6 \%$ \\
\hline Total & 114 & 81 & 55 & 46 & 296 \\
Teste Qui-quadrado: Sig. 0,011 $100,0 \%$ & $100,0 \%$ & $100,0 \%$ & $100,0 \%$ & $100,0 \%$ \\
\hline \multicolumn{5}{|c|}{ TABELA 2- O enquadramento das politicas ambientais ${ }^{2}$} \\
Fonte: Autores
\end{tabular}

Os dados da tabela acima permitem identificar que há uma relação significativa entre o enquadramento dos textos e o tema das políticas. Aplicando o teste de Qui-quadrado, o nível de significância está dentro do esperado para comprovar que há relação entre as duas variáveis. O tema sustentabilidade aparece equilibrado nos textos temáticos e episódicos, porém, ao observar preservação, legislação e política de devastação, percebe-se que estes temas estão mais presentes quando o enquadramento é episódico. A diferença no caso de preservação, por exemplo, é $66,7 \%$ no enquadramento episódico e $33,3 \%$ no temático. Esses valores mostram que o tema sustentabilidade, independentemente de acontecimentos factuais, ganha espaço no jornal, enquanto os demais apareceram sempre relacionados a casos factuais, sendo que sem estes a chance de ganharem visibilidade seria menor. A tabela a seguir (tabela 3) apresenta a relação entre a posição dos textos e os temas e tem por 
objetivo identificar se estes se apresentam nos espaço de maior ou menor visibilidade.

\begin{tabular}{|c|c|c|c|c|c|}
\hline Posição & Sustentabilidade & Preservação & Legislação & $\begin{array}{c}\text { Pol/ } \\
\text { devastação }\end{array}$ & Total \\
\hline $\begin{array}{l}\text { Metade } \\
\text { Superior }\end{array}$ & $\begin{array}{r}83 \\
62,9 \%\end{array}$ & $\begin{array}{r}53 \\
63,9 \%\end{array}$ & $\begin{array}{r}33 \\
47,8 \%\end{array}$ & $\begin{array}{r}23 \\
45,1 \% \\
\end{array}$ & $\begin{array}{r}192 \\
57,3 \%\end{array}$ \\
\hline $\begin{array}{l}\text { Metade } \\
\text { Inferior }\end{array}$ & $\begin{array}{r}49 \\
37,1 \% \\
\end{array}$ & $\begin{array}{r}30 \\
36,1 \% \\
\end{array}$ & $\begin{array}{r}36 \\
52,2 \% \\
\end{array}$ & $\begin{array}{r}28 \\
54,9 \% \\
\end{array}$ & $\begin{array}{r}143 \\
42,7 \% \\
\end{array}$ \\
\hline Total & $\begin{array}{r}132 \\
100,0 \%\end{array}$ & $\begin{array}{r}83 \\
100,0 \%\end{array}$ & $\begin{array}{r}69 \\
100,0 \%\end{array}$ & $\begin{array}{r}51 \\
100,0 \%\end{array}$ & $\begin{array}{r}335 \\
100,0 \%\end{array}$ \\
\hline
\end{tabular}

TABELA 3 - Distribuição dos temas de acordo com a posição do texto ${ }^{3}$

Fonte: Autores

A relação entre os temas e a visibilidade na página é significativa de acordo com o teste de Qui-quadrado que mostrou um sig. igual a 0,032, o que rejeita a hipótese nula e sustenta a hipótese alternativa de que há relação entre as variáveis. Percebe-se, a partir dos dados presentes na tabela, que enquanto as políticas contra devastação apresentam-se distribuídas nas duas dobras da página, assim como legislação, as políticas de sustentabilidade e preservação apresentam-se predominantemente nos primeiros quadrantes, ou seja, no espaço de maior visibilidade. Assim, além de aparecerem mais do que as demais políticas, estão em espaços mais visíveis. De modo geral, observa-se que os tipos de política aparecem de forma desigual no Jornal Gazeta do Povo. Ao observar o número de entradas, o tipo de enquadramento e a posição, percebe-se que as políticas de sustentabilidade e preservação ganham mais destaque na cobertura, além de manterem-se mais estáveis durante todo o período. Para complementar a análise, abaixo são apresentados os resultados da variável "etapa do ciclo político", na qual é possível identificar em que momento a mídia faz a cobertura das ações governamentais.

\begin{tabular}{lrr} 
Etapa do "Polyce Cycle” & Frequência & $\%$ \\
\hline Agenda e Elaboração & 104 & 28,3 \\
Formulação & $\mathbf{6 5}$ & 17,7 \\
Implementação & 24 & 6,5 \\
Execução & $\mathbf{9 8}$ & $\mathbf{2 6 , 7}$ \\
Acompanhamento & 34 & 9,3 \\
Avaliação & 21 & 5,7 \\
Indefinida & 21 & 5,7 \\
Total & 367 & 100,0
\end{tabular}

TABELA 4 - Etapa do Ciclo Político em que a mídia faz a cobertura das políticas Fonte: Autores

Essa tabela permite identificar quando o Jornal Gazeta do Povo faz a cobertura sobre as políticas públicas - neste caso, as ações para o meio ambiente. Ao analisar aos dados acima, é possível perceber que a cobertura feita pelo jornal se concentra basicamente em dois momentos: na discussão prévia $(28,3 \%)$ e na execução $(26,7 \%)$. Estes dados refutam a hipótese inicial de que o veículo apenas noticiava textos referentes à “divulgação” das ações do governo no mo- 
mento Formulação e Execução de Políticas. A hipótese tinha como pressuposto que o agendamento de temas pelo governo se concentrava apenas em textos que poderiam mostrar a ação do governo propriamente dita, seja na aprovação de leis e projetos ou na colocação das ações em prática. Porém os dados coletados mostram que, apesar das notícias sobre execução aparecerem com $26,7 \%$ do total de entradas, o momento em que a mídia mais aborda o tema é no processo de agendamento do problema e elaboração da política $(28,3 \%)$, no qual é, de fato, importante o papel da mídia para a divulgação do debate sobre o assunto, pois é anterior a formulação da própria política. Em seguida dos textos sobre execução das ações, aparece a cobertura sobre a formulação das políticas com $17,7 \%$ e, posteriormente, com uma presença menor estão as etapas de acompanhamento, implementação e avaliação das ações do governo. Apesar da cobertura não aparecer de forma equilibrada em todos os momentos do ciclo político, os dados refutam a hipótese inicial deste trabalho e mostram que no momento de elaboração, o qual é importante a informação e debate, há maior produção jornalística. Para complementar, o gráfico abaixo (Gráfico 2)

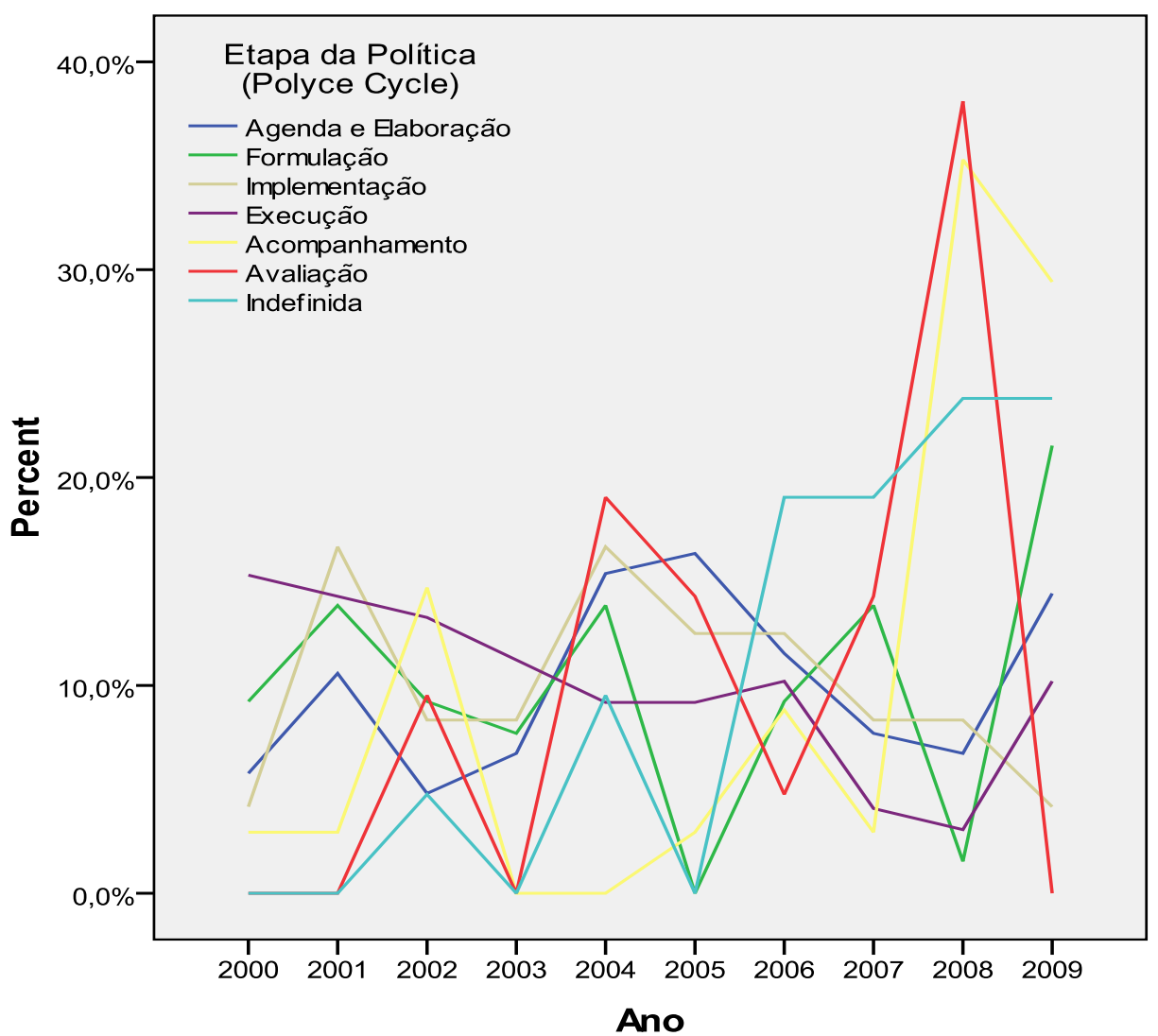

apresenta a variação da cobertura durante todo o período analisado. GRÁFICO 2 - Cobertura do ciclo politico de 2000 a 2009

Fonte: Autores

Os dados apresentados no gráfico mostram que o tipo de cobertura depende do período observado. Algumas etapas apresentam uma variação maior do que as demais, como é o caso da cobertura sobre a avaliação das políticas que tem um salto em 2004 e 2008, mantendo-se baixa no restante do período. Dessa mesma forma aparece a cobertura sobre acompanhamento, com mais entradas em 2002 e 2008. E textos catalogados como Indefinidos - por não 
haver identificação da etapa da política - também crescem a partir de 2006. As demais etapas do ciclo político aparecem durante todo o período variando entre $0 \%$ e $20 \%$, sem períodos de pico, mantendo-se mais estáveis. E mesmo fazendo parte dos temas que se apresentam mais estáveis durante todo o período, percebe-se que Implementação e Execução apresentam-se em queda. Implementação, a partir de 2004 , e execução foram aparecendo cada vez menos na cobertura desde o ano 2000 até 2008, apresentando uma pequena elevação somente em 2009. A tabela abaixo mostra como a cobertura da mídia sobre as etapas do ciclo político também varia conforme a abrangência dos textos.

\begin{tabular}{|c|c|c|c|c|c|}
\hline Abrangência & $\begin{array}{l}\text { Agenda e } \\
\text { Elaboração }\end{array}$ & $\begin{array}{c}\text { Formulação e } \\
\text { Implementação }\end{array}$ & Execução & $\begin{array}{c}\text { Acompanhamento } \\
\text { e Avaliação }\end{array}$ & Total \\
\hline \multirow[t]{2}{*}{ Local } & 14 & 14 & 20 & 13 & 61 \\
\hline & $15,1 \%$ & $17,1 \%$ & $21,3 \%$ & $23,6 \%$ & $18,8 \%$ \\
\hline \multirow[t]{2}{*}{ Estadual } & 46 & 30 & 69 & 23 & 168 \\
\hline & $49,5 \%$ & $36,6 \%$ & $73,4 \%$ & $41,8 \%$ & $51,9 \%$ \\
\hline \multirow[t]{2}{*}{ Nacional } & \multirow{2}{*}{$\begin{array}{r}33 \\
35,5 \%\end{array}$} & \multirow{2}{*}{$\begin{array}{r}38 \\
46,3 \%\end{array}$} & \multirow{2}{*}{$\begin{array}{r}5 \\
5,3 \%\end{array}$} & \multirow{2}{*}{$\begin{array}{r}19 \\
34,5 \%\end{array}$} & 95 \\
\hline & & & & & $29,3 \%$ \\
\hline \multirow[t]{2}{*}{ Total } & 93 & 82 & 94 & 55 & 324 \\
\hline & $100,0 \%$ & $100,0 \%$ & $100,0 \%$ & $100,0 \%$ & $100,0 \%$ \\
\hline
\end{tabular}

Fonte: Autores

A tabela mostra que a cobertura da mídia sobre cada etapa do ciclo político está relacionada com a abrangência dos textos, sendo que a relação entre as duas variáveis é significativa de acordo com o resultado do Teste Qui-quadrado (sig. 0,000 ). A produção jornalística sobre a agenda e elaboração"concentra-se nos textos de abrangência estadual (49,5\%), assim como os de formulação e implementação das políticas (46,3\%) estão mais concentrados nos de abrangência nacional, sendo que isso está relacionado com o fato de que a maior parte das políticas públicas são de abrangência nacional, sendo as decisões tomadas a nível nacional. De forma diferente, execução aparece mais centralizada predominantemente em textos de abrangência estadual, com mais de $70 \%$ das entradas. Mais equilibrado aparece a cobertura sobre acompanhamento e avaliação, concentrada em textos de abrangência estadual (41,8\%), sendo o restante distribuído em nacional $(34,5 \%)$ e local $(23,6 \%)$. De forma geral, a cobertura da mídia aparece centralizada em algum momentos do ciclo político e variando bastante conforme o período observado, assim como está relacionada com a abrangência dos textos.

\section{Considerações Finais}

Os dados apresentados nesse artigo mostram que a cobertura das ações do governo para o meio ambiente no Jornal Gazeta do Povo não se apresenta de forma equilibrada quando observados os temas e o momento do ciclo político em que a mídia faz a cobertura. Dessa forma, é possível afirmar que o jornal não contribui para o debate sobre alguns assuntos. $\mathrm{O}$ resultado da pesquisa 
revela que alguns temas possuem maior número de entradas do que outros como é o caso das políticas de sustentabilidade (36\%) em comparação com as de educação ambiental (2,2\%). Muitos deles, além de não aparecerem em grande quantidade durante o período analisado, se apresentam em momentos específicos, o que está relacionado com alguns acontecimentos, como é o caso do tema legislação, que aparece bastante em 2009 (mais de 30\% das entradas sobre esse tema está concentrado nesse ano), mas quase nem aparece em outros momentos da cobertura. Ou seja, o tema aparece no jornal muito mais como um assunto episódico do que como uma discussão permanente no veículo. Esses dados afirmam a primeira hipótese do trabalho que defendia o não equilíbrio da cobertura, centralizando-a em determinados temas. Como foram observados, alguns assuntos aparecem mais que outros que se tornam quase insignificantes quando comparados com o restante da cobertura.

Além disso, a própria cobertura durante os 10 anos passa por modificações, o que está relacionado com os acontecimentos factuais que ajudam a moldar a cobertura. O Gráfico 1 mostra, por exemplo, como alguns temas aparecem durante todo o período e outros apenas em momentos específicos. Dessa forma, o debate sobre as políticas públicas ambientais se dá de forma fragmentada, centralizada em determinados assuntos, enquanto os demais dependem de fatos para ganharem espaço na cobertura. Por meio desses resultados, pode-se concluir que nem todos os temas ganham, por meio da mídia, espaço no debate público. Ressalta-se, ainda, que isso está relacionado com a presença maior de enquadramento episódico $(58,4 \%)$ do que temático - sendo que este último possibilitaria um debate mais frequente no jornal - e também com a pouca visibilidade que alguns temas possuem por estarem predominantemente presentes na segunda dobra da página enquanto outros aparecem mais na primeira.

O debate sobre as políticas públicas ambientais se dá de forma fragmentada, centralizada em determinados assuntos

Observando a outra variável discutida neste trabalho, a qual trata dos momentos em que se dá a cobertura das políticas de acordo com o ciclo político, percebe-se que a cobertura também se apresenta centralizada em dois momentos: na etapa de execução e na de elaboração e agenda. Em seguida aparece formulação, e posteriormente e em menor quantidade as demais etapas. Dessa forma, os dados apresentados nesse artigo permitiram afirmar a primeira hipótese proposta, pois a mídia promoveu durante esses 10 anos um debate centralizado em alguns temas em detrimento de outros. Porém, a segunda hipótese é refutada, pois a idéia inicial de que a mídia fazia apenas cobertura de divulgação das ações do governo não se confirma. Apesar da etapa execução aparece em segundo lugar com $26,4 \%$ das entradas coletadas, agenda e elaboração, que é um dos momentos importantes da cobertura para o debate público, aparece com 28,3\%. Dessa forma, a mídia também oferece espaço para o debate anterior as decisões da elite política na formulação das leis, projetos e programas, e não apenas como se imaginava anteriormente, no qual as ações do governo apenas ganhariam espaço na agenda da mídia como forma de divulgação das ações. Dando espaço para o debate que antecede as decisões da elite política, o jornal contribui não apenas para a informação do leitor, mas também o debate a cerca das decisões que, posteriormente, podem 
ser resultadas em projetos e programas ambientais. Ressalta-se, porém, que diferente dessas etapas, outras quase não aparecem na cobertura, como é o caso de avaliação com 5,7\% das entradas. Ou seja, a cobertura também se apresenta fragmentada quanto ao momento em que o jornal dá espaço para a discussão das políticas. Outro dado importante está presente no Gráfico 2 e mostra que a cobertura sobre o tema, quando observado o momento do ciclo político, também se dá de forma bastante oscilante ao longo do período estudado. Algumas etapas, além de aparecerem em menor quantidade no jornal, não estão presentes em todos os anos. A mídia apresenta a sua cobertura centralizada em alguns temas e também em momentos específicos da organização da política, promovendo um debate bastante parcial para o leitor.

Ressaltamos que apenas com esses dados não é possível afirmar de que modo se dá o debate a respeito do assunto entre os diferentes tipos de atores presentes na cobertura feita pelo jornal, nem em que medida essa produção jornalística incide no debate público. Porém, partimos do pressuposto da relação entre a agenda da mídia e da agenda do público já proposta por outros autores, tais como McCombs e Shaw, que já mostravam, em 1972, a incidência de mesmos temas em ambas as agendas. Sendo assim, é possível dizer que a mídia faz a cobertura das políticas públicas, porém, esse debate não se apresenta equilibrado quanto aos temas/áreas das políticas e nem ao momento do ciclo político, o que pode contribuir para um debate fragmentado do público que se utiliza dos meios de comunicação para formar a opinião e se informar, podendo, posteriormente, contribuir com o debate público sobre este assunto na sociedade e, ainda, influenciar na formação da agenda política.

\footnotetext{
O resultado do teste é 0,000, o que indica uma relação forte entre os temas e a variação em cada período de tempo. Para fazer o teste de significância foi necessário considerar como missing as categorias "outros" e "educação ambiental", pois apresentavam um número muito pequeno de casos, o que poderia distorcer os resultados do teste.

2 Da mesma forma que o teste anterior, foi necessário retirar da tabela e considerar como missing as categorias "outros" e "educação ambiental", pois apresentavam um número muito pequeno de casos, o que poderia distorcer os resultados do teste.

3 Para fazer o teste de significância também foi necessário retirar da tabela e considerar como missing as categorias "outros" e "educação ambiental", da mesma forma que na tabela anterior, pois apresentavam um número muito pequeno de casos, o que poderia distorcer os resultados do teste.

${ }^{4}$ Para fazer o teste de significância foi retirado da tabela e considerado como missing as categorias internacional e indefinida da variável categórica "abrangência do texto", assim como foi necessário agregar as categorias da variável "etapa do ciclo político" e considerar a categoria indefinido também como missing. Estas categorias apresentavam um número muito pequeno de casos, o que poderia distorcer os resultados do teste.
}

\section{Referências bibliográficas}

ARUGUETE, N. Los medios de comunicación y la formación de la agenda pública. Verso e Reverso - revista de comunicação, Unisinos. n ${ }^{\circ}$ 41, 2005/2. BAUER, M. Análise de conteúdo clássica: uma revisão. In: BAUER, Martin W.; GASKELL, George (org.). Pesquisa qualitativa com texto, imagem e som: um manual prático. Petrópolis: Vozes, 2002.

CAPELlA, A. Formação da Agenda Governamental: Perspectivas Teóricas. 
In: Anais do XXIX Encontro Anual da ANPOCS, 25 a 29 de outubro de 2005, Caxambu - MG.

CERVI, E. Métodos quantitativos nas ciências sociais: uma abordagem alternativa ao fetichismo dos números e ao debate com qualitativas. In: AYRES, J. B. (Org.) Pesquisa Social: reflexões teóricas e metodológicas. Ponta Grossa: Toda Palavra Editora, 2009.

COIMBRA, M. A mídia teve algum papel durante o processo eleitoral de 2006. In: LIMA, V (org). A mídia nas eleições de 2006. São Paulo: Fundação Perseu Abramo, 2007.

DAVIS, J. A. Levantamento de Dados em Sociologia: uma análise estatística elementar. Rio de Janeiro - RJ: Zahar Editores, 1976.

GOMES, Wilson. Publicidade, visibilidade e discutibilidade. In: Trabalho apresentado no XVI Encontro da Compós. Curitiba: 2007

GUARECHI, P. Mídia e democracia: o quarto versus o quinto poder. In: Revista Debates, Porto Alegre, v.1, n.1, p. 6-25, jul.-dez. 2007.

HANSEN, M. Esfera pública, democracia e jornalismo: as representações sociais de cidadania em 'Veja' e'Isto É'. São Cristóvão: Editora UFS, 2007. LIMA, L. As Políticas Públicas para o Meio Ambiente. In: Recanto das Letras, 2008

MAIA, R. Mídia e deliberação pública: mediações possíveis. In: Anais da XI Reunião anual da COMPÓS, de 4 de junho de 2002 a 7 de junho de 2002: Rio de Janeiro - RJ, 2002.

McCOMBS, M; SHAW, D. The Agenda-Setting Function of Mass Media. In: Public Opinion Quarterly 36, 1972, p. 176-187.

MARQUES, A. Os meios de comunicação na esfera pública: novas perspectivas para as articulações entre diferentes arenas e atores. $\mathrm{N}^{\circ} 21$. Líbero: 2008.

MIGUEL, L. Os meios de comunicação e a prática política. In: Lua Nova. $\mathrm{N}^{\mathrm{O}}$ 55-56. 2002.

MIGUEL, L. Um ponto cego nas Teorias da Democracia: os Meios de Comunicação. In: Revista Brasileira de Informação Bibliográfica em Ciências Sociais - BIB. No 49, R. Janeiro: 2000.

RESENDE, F. Comunicação e complexidade no espaço público contemporâneo. In: Revista On-line Unileste: Sem data.

SHOEMAKER, P.; VOS, T. Gatekeeping Theory. 1a edição. New York: Routledge, 2009.

SOUZA, C. Políticas Públicas: uma revisão da literatura. In: Sociologias. $\mathrm{N}^{\mathrm{O}}$ 16, jul/dez 2006.

TEJEIRO, C. Las fronteras del (des)ordem: Acerca de los médios, de la democracia y el nuevo espacio-público ciudano. In: Revista Comunicação e Espaço Público. Brasília: 2006.

TUCHMAN, G. Contando "Estórias". In: TRAQUINA, N. Jornalismo: Questões, Teorias e "Estórias". Lisboa: Vegas, 1993. 